\title{
Aging-related sex-dependent loss of the circulating leptin 24-h rhythm in the rhesus monkey
}

\author{
Jodi L Downs and Henryk F Urbanski \\ Division of Neuroscience, Oregon National Primate Research Center, Beaverton, Oregon 97006 and Department of Physiology and Pharmacology, Oregon \\ Health \& Science University, Portland, Oregon 97239, USA \\ (Requests for offprints should be addressed to H F Urbanski; Email: urbanski@ohsu.edu)
}

\begin{abstract}
The adipocyte-derived hormone leptin plays a pivotal role in the regulation of body weight and energy homeostasis. Many studies have indicated that the circulating levels of leptin show a 24-h rhythm, but the exact cause and nature of this rhythm is still unclear. In the present study, we remotely collected blood samples every hour from young and old, male and female rhesus monkeys, and examined their 24-h plasma leptin profiles. In both the young males (10-11 years) and females (7-13 years), a clear 24-h plasma leptin rhythm was evident with a peak occurring $\sim 4 \mathrm{~h}$ into the night and a nadir occurring $\sim 1 \mathrm{~h}$ into the day (lights on from 0700 to 1900 h). A 24-h plasma leptin rhythm was also observed in

the old males (23-30 years), even when they were maintained under constant lighting conditions (continuous dim illumination of $\sim 1001 \mathrm{x})$. In marked contrast, plasma leptin concentrations were relatively constant across the day and night in old peri- and post-menopausal females (17-24 years), regardless of the lighting schedule. These data establish that rhesus monkeys, like humans, show a daily nocturnal rise in plasma leptin, and the magnitude of this rhythm undergoes a sex-specific aging-dependent attenuation. Furthermore, they suggest that the underlying endocrine mechanism may be driven in part by a circadian clock mechanism.

Journal of Endocrinology (2006) 190, 117-127
\end{abstract}

\section{Introduction}

Leptin, the adipocyte-derived hormone product of the obese (ob) gene, provides feedback information about the status of peripheral energy stores to the brain, and thereby plays an important role in regulating energy homeostasis and body weight (Zhang et al. 1994, Campfield et al. 1995, Halaas et al. 1995, Pelleymounter et al. 1995, Stephens et al. 1995, Weigle et al. 1995). Many factors are involved in determining the concentration of leptin in the circulation, including: fat mass, caloric intake, meal timing and frequency, circulating glucose and insulin (Considine 2001, Havel 2002), sex and the sex steroids estradiol and testosterone (Casabiell et al. 2001, Mayes \& Watson 2004), and adrenal steroids (Casabiell et al. 2001, Considine 2001, Leal-Cerro et al. 2001). Although the level of leptin in the circulation generally correlates well with the level of stored fat, there is also evidence to indicate that leptin levels vary markedly during the day. For example, a nocturnal rise in circulating leptin concentrations has been observed both in lean and obese humans, as well as in individuals with type II diabetes (Sinha et al. 1996a, Langendonk et al. 1998, Simon et al. 1998). In addition, a detailed examination of 24-h leptin concentrations revealed a superimposed pulsatile secretory pattern of leptin in lean and obese individuals (Sinha et al. 1996b, Licinio et al. 1997, Simon et al. 1998). Non-human primate data supporting a diurnal variation in circulating leptin are less clear. This variation has only been observed utilizing two sampling points over the 24-h day in male rhesus monkeys (Macaca mulatta) during late pre-puberty (Suter et al. 2000) and has yet to be determined in adult monkeys. Rodent studies have demonstrated a nocturnal rise in circulating leptin levels as well as in leptin mRNA expression in adipose tissue (Saladin et al. 1995). So far, however, neither the genesis of the 24-h leptin rhythm has been elucidated nor is it clear what the physiological significance of a diurnal variation in circulating leptin may be. A disruption of this rhythm may contribute to body weight dysregulation and obesity (Laughlin \& Yen 1997, Matkovic et al. 1997, Balligand et al. 1998, Støving et al. 1998) and an interference in the maintenance of bone mass (Ducy et al. 2000, Elefteriou et al. 2005). This could be particularly evident during aging, as loss of circadian rhythmicity or an attenuation of the amplitude of many circadian rhythms appears to be a characteristic of aging (Schwartz 1993, Touitou et al. 1997, Touitou \& Haus 2000, Downs et al. 2001, Pandi-Perumal et al. 2002, Urbanski et al. 2004). Little is currently known about the effect of aging on the 24-h pattern of circulating leptin. However, moderate dampening of nocturnal leptin levels has been reported in old men, and with advancing age the acrophase of the leptin rhythm appears to occur earlier in the day (Franceschini et al. 1999, Zhao et al. 2002). 
Possible endocrine candidates influencing the 24-h release of leptin include cortisol and dehydroepiandrosterone sulfate (DHEAS). Cortisol and DHEAS are released from the adrenal cortex in a circadian fashion, i.e. antiphase to the release pattern of leptin (Urbanski et al. 2004). However, cortisol and DHEAS appear to exert opposing effects on leptin release. Cortisol acts directly on adipose tissue to stimulate leptin synthesis and secretion in both sexes, while DHEAS inhibits leptin release from adipose tissue from female donors (Casabiell et al. 2001, Considine 2001, Leal-Cerro et al. 2001). Although glucocorticoid administration stimulates leptin production, they appear to play a modulatory role and are not necessary in generating a leptin diurnal rhythm. Patients lacking endogenous cortisol secretion retained a normal 24-h leptin rhythm when injected with saline only and when given replacement hydrocortisone infusions with normal or reversed diurnal patterns (Purnell \& Samuels 1999). Additionally, we have previously reported in rhesus monkeys, a marked aging-related decline in plasma DHEAS concentrations and an associated attenuation of its diurnal variation. In contrast, plasma cortisol concentrations did not significantly differ with age (Urbanski et al. 2004, Aghazadeh-Sanai et al. 2005). Further, the decline in plasma DHEAS concentrations was observed at an earlier age in females than in males (Urbanski et al. 2004, Aghazadeh-Sanai et al. 2005). Given these observations, we chose to focus our investigation on the possible correlation between plasma DHEAS, rather than cortisol, and leptin concentrations during aging.

The aims of the present study were twofold: (1) to evaluate the effect of aging on the 24-h pattern of circulating leptin in the male and female non-human primate, and (2) to determine if the circulating 24-h leptin rhythm persists under constant environmental conditions (lighting, temperature, and masked auditory cues). To address these issues, we chose to utilize the rhesus monkey as our animal model. This model closely resembles the human in terms of its physiology, circadian rhythmicity, menopause, and aging. Moreover, rhesus monkeys can be maintained under tightly controlled environmental conditions and can have serial blood samples collected remotely. Preliminary data from this study have previously been published in abstract form (Downs \& Urbanski 2003).

\section{Materials and methods}

\section{Animals and experimental groups}

To evaluate sex-specific aging-related effects on the 24-h circulating leptin rhythm in the non-human primate, 28 adult rhesus monkeys were divided into five groups based upon sex, age, and reproductive status (Tables 1 and 2). The animals were housed in a temperature-controlled environment $\left(24^{\circ} \mathrm{C}\right)$, under a $12 \mathrm{~h}$ light: $12 \mathrm{~h}$ darkness photoperiod, with meal times at 0800 and $1500 \mathrm{~h}$ (Purina High Protein Monkey Chow No. 5045; Purina Mills, Inc., St Louis, MO, USA). Chow consumed per meal consisted of 100-125 g for males and $45-50 \mathrm{~g}$ for females regardless of age group, and the duration

Table 1 Analysis of male rhesus monkey 24-h plasma hormone profiles

Body weight $(\mathrm{kg})$

Mean leptin $(\mathrm{ng} / \mathrm{ml})$

Peak leptin $(\mathrm{ng} / \mathrm{ml})$

Nadir leptin $(\mathrm{ng} / \mathrm{ml})$

Fasting leptin $(\mathrm{ng} / \mathrm{ml})$

Fasting DHEAS (ng/ml)

Mean testosterone $(\mathrm{ng} / \mathrm{ml})$
Fasting insulin $(\mu \mathrm{U} / \mathrm{ml})$

\begin{tabular}{c} 
Young $(n=10)$ \\
\hline $9 \cdot 5 \pm 0 \cdot 6$ \\
$1 \cdot 3 \pm 0 \cdot 2$ \\
$1 \cdot 8 \pm 0 \cdot 3$ \\
$0 \cdot 6 \pm 0 \cdot 2$ \\
$0 \cdot 8 \pm 0 \cdot 2$ \\
$11 \cdot 4 \pm 1 \cdot 8$ \\
$217 \cdot 0 \pm 24 \cdot 4$ \\
$5 \cdot 8 \pm 0 \cdot 47$
\end{tabular}

Values represent mean \pm S.E.M. Blood samples to determine fasting plasma leptin, insulin, and DHEAS were collected at $0700 \mathrm{~h}$ after an overnight fast and before the AM meal. Young $=10-11$ years, old $=23-30$ years. ${ }^{a} P<$ $0 \cdot 05,{ }^{b} P<0 \cdot 01,{ }^{c} P<0 \cdot 0001$ vs young males (Student's $t$-test).

of each meal was less than $2 \mathrm{~h}$ for each group. Remote monitoring of their physical activity, using Actiwatch recorders (Mini Mitter Company, Inc., Sunriver, OR, USA) showed that their activity occurred while lights were on (0700-1900 h). One milliliter of blood sample was collected hourly for $25 \mathrm{~h}$ using a remote blood sampling system (see below) from all 28 animals. Samples were collected from young $(10 \cdot 6 \pm 0 \cdot 08$ years; $n=10)$ and old $(26 \cdot 3 \pm 0 \cdot 89$ years; $n=7)$ males starting at $1900 \mathrm{~h}$ and samples were collected from young $(9 \cdot 3 \pm 1 \cdot 40$; $n=4)$, old pre-menopausal $(20 \cdot 5 \pm 1 \cdot 67$ years; $n=3)$, and old peri- and post-menopausal $(21 \cdot 7 \pm 0 \cdot 67$ years; $n=8)$ females starting at $0700 \mathrm{~h}$. The purpose of the different collection start times was to eliminate the possibility that any plasma leptin rhythm found was an artifact of the blood collection paradigm.

To determine if the 24-h circulating leptin rhythm may be driven by an underlying circadian clock, five old males $(26 \cdot 4 \pm 1 \cdot 18$ years) and seven old peri- and post-menopausal females $(22 \cdot 3 \pm 0 \cdot 24$ years $)$ were maintained under the following constant environmental conditions: constant temperature $\left(24^{\circ} \mathrm{C}\right)$, continuous dim illumination $(\sim 100 \mathrm{~lx})$, and masking of vocalized social cues of other nearby animals by playing a 2-h loop of recorded 'background' sounds made by monkeys within the housing area. The animals were maintained under constant conditions for 2 or more weeks to allow for their endogenous circadian rhythms to 'free-run'. During this time, the animals continued to have consolidated sleep/wake cycles. These were monitored using Actiwatch recorders, which were housed in a pocket on the back of a catheter-protection jacket. After the 2-week period, $1 \mathrm{ml}$ of blood sample was collected hourly for $25 \mathrm{~h}$ using the remote blood sampling system (see below). Sample collection started at $1900 \mathrm{~h}$ for males and at $0700 \mathrm{~h}$ for females.

\section{Remote blood collection}

Each animal was surgically fitted with an indwelling subclavian catheter as previously described (Urbanski et al. 1997) to enable i.v. blood sampling from an adjacent room without disturbing the animal. Briefly, this consisted of a swivel apparatus at the top of the cage and a protective stainless-steel 
Table 2 Analysis of female rhesus monkey 24-h plasma hormone profiles

\begin{tabular}{|c|c|c|c|}
\hline & \multicolumn{2}{|l|}{ Pre-menopause } & \multirow{2}{*}{$\frac{\text { Peri/post-menopause }}{\text { Old }(n=8)}$} \\
\hline & Young $(n=4)^{*}$ & Old $(n=3)$ & \\
\hline Body weight (kg) & $5 \cdot 9 \pm 0 \cdot 4^{b}$ & $6 \cdot 1 \pm 0 \cdot 5^{b}$ & $7 \cdot 5 \pm 0 \cdot 3$ \\
\hline Mean leptin (ng/ml) & $1 \cdot 7 \pm 0 \cdot 5$ & $2 \cdot 5 \pm 1 \cdot 4$ & $5 \cdot 1 \pm 0 \cdot 7^{\mathrm{a}}$ \\
\hline Peak leptin (ng/ml) & $2 \cdot 4 \pm 0 \cdot 6$ & $3 \cdot 0 \pm 1 \cdot 2$ & $6 \cdot 2 \pm 0 \cdot 9^{\mathrm{a}}$ \\
\hline Nadir leptin (ng/ml) & $1 \cdot 1 \pm 0 \cdot 5^{c}$ & $1 \cdot 2 \pm 0 \cdot 6^{\mathrm{c}}$ & $3 \cdot 9 \pm 0 \cdot 4$ \\
\hline Fasting leptin $(\mathrm{ng} / \mathrm{ml})$ & $1 \cdot 4 \pm 0 \cdot 4^{c}$ & $2 \cdot 0 \pm 1 \cdot 6^{b}$ & $5 \cdot 0 \pm 0 \cdot 6$ \\
\hline Fasting insulin $(\mu \mathrm{U} / \mathrm{ml})$ & $23 \cdot 9 \pm 4 \cdot 7$ & $32 \cdot 8 \pm 5 \cdot 0$ & $36 \cdot 1 \pm 8 \cdot 9$ \\
\hline Fasting DHEAS (ng/ml) & $86 \cdot 4 \pm 15 \cdot 0$ & $23 \cdot 2 \pm 3 \cdot 9^{a}$ & $34 \cdot 6 \pm 6 \cdot 5^{a}$ \\
\hline
\end{tabular}

Values represent mean \pm s.E.M. Blood samples to determine fasting plasma leptin were collected after an overnight fast and before the AM meal. Young $=7-13$ years, old pre-menopausal $=17-22$ years, old peri/post-menopausal $=17-24$ years. ${ }^{a} P<0 \cdot 05$ vs young females, ${ }^{b} P<0 \cdot 05$ vs old peri/post-menopausal females, ${ }^{c} P<0 \cdot 01$ vs old peri/post-menopausal females (one-way randomized ANOVA, Newman-Keuls post-analysis).

*Fasting insulin values were determined for three young females rather than four due to the unavailability of plasma.

tether (Lomir Biomedical, Inc., Malone, NY, USA); to maintain catheter patency, heparinized saline $(5 \mathrm{IU} / \mathrm{ml})$ was continuously infused $(\sim 1 \mathrm{ml} / \mathrm{h})$ using a peristaltic pump. Reproductive status of the young and old females was determined by detailed menstruation records and analysis RIA of blood samples for $17 \beta$-estradiol and progesterone (Resko et al. 1974, 1975, Gundlah et al. 2000). All the young and old pre-menopausal females were sampled from and during the mid-late follicular phase (days 5-12 of a $\sim 28$ day cycle) of their menstrual cycles.

This study was approved by the Institutional Animal Care and Use Committee of the Oregon National Primate Research Center (ONPRC), and animal care was provided by the ONPRC in accordance with the NIH Guide for the Care and Use of Laboratory Animals.

\section{Hormone assays}

Serial blood samples were remotely collected in EDTA-coated tubes at $1-\mathrm{h}$ intervals across the day and night for $25 \mathrm{~h}$ and then centrifuged at $4{ }^{\circ} \mathrm{C}$; the plasma supernatant was removed and stored at $-20^{\circ} \mathrm{C}$. Plasma leptin concentrations were determined by RIA (Linco Research, Inc., St Charles, MO, USA) with a detection limit of $0 \cdot 25 \mathrm{ng} / \mathrm{ml}$. The intra-assay coefficients of variation were $5 \cdot 6 \%$ at $3 \cdot 5 \mathrm{ng} / \mathrm{ml}$ and $6 \cdot 0 \%$ at $21 \cdot 1 \mathrm{ng} / \mathrm{ml}$. The corresponding inter-assay coefficients of variation were 7.9 and $7 \cdot 0 \%$ respectively. Plasma insulin concentrations were determined by electrochemiluminescence using the Elecsys 2010 System (Roche); the assay limit of sensitivity was $0 \cdot 2 \mu \mathrm{U} / \mathrm{ml}$ and the intra-assay coefficient of variation was $4 \cdot 5 \%$. Plasma testosterone and DHEAS concentrations were determined by RIA as previously described (Resko et al. 1973, Urbanski et al. 2004).

\section{Statistical analysis}

Twenty-four-hour plasma leptin concentrations were assessed both as raw values $(\mathrm{ng} / \mathrm{ml})$ as well as percent variability $(\%$ of mean). Student's $t$-test was used to evaluate group differences in body weight, as well as mean, fasting (after an overnight fast and prior to the AM meal), peak, and nadir raw plasma leptin concentrations between young and old males. One-way randomized ANOVA followed by the Newman-Keuls multiple range test was used to evaluate group differences in body weight, as well as mean, fasting (after an overnight fast and prior to the AM meal), peak, and nadir raw plasma leptin concentrations between young, old pre-menopausal, and old peri- and old post-menopausal females. Variability was defined as a percentage of the individual 24-h mean using the formula:

Variability at time $t=\left(\frac{\text { hormone concentration at time } t}{24-\mathrm{h} \text { individual mean concentration }}\right) \times 100$

Plasma leptin variability was plotted against time for each group, and was analyzed using one-way repeated measures ANOVA. Values significantly different from the nadir value were then determined by the Dunnett's-test, and a $P$-value of $<0 \cdot 05$ was used to indicate statistical significance.

Group differences in 24-h mean testosterone, fasted morning plasma insulin, and DHEAS concentrations were determined by Student's $t$-test between young and old males. Group differences in fasted morning plasma insulin and DHEAS concentrations were determined by one-way randomized ANOVA followed by the Newman-Keuls multiple range test between young, old pre-menopausal, and old peri- and old post-menopausal females. The relationships between age and fasted morning plasma leptin, insulin, and DHEAS concentrations and between 24-h mean plasma leptin and fasted morning DHEAS concentrations were determined by Pearson's correlation analysis.

\section{Results}

Comparison of 24-h leptin profiles in young and old male rhesus monkeys

Significant diurnal variation of plasma leptin was evident in both the young $(P<0 \cdot 01)$ and old $(P<0 \cdot 05)$ males (Fig. 1). However, some quantitative and qualitative differences were 


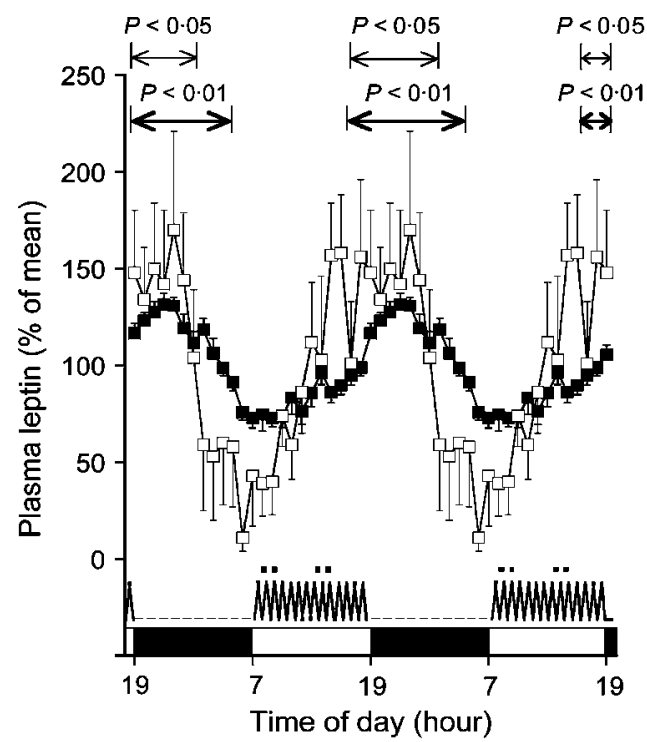

Figure 1 24-h plasma leptin concentrations in young adult male rhesus monkeys ( $\boldsymbol{\square} ; n=10)$ and old male rhesus monkeys ( $\square ; n=7)$. The horizontal black and white bar on the abscissa corresponds to the $12 \mathrm{~h}$ light:12 h darkness lighting schedule. The monkeys were fed two meals daily at 0800 and $1500 \mathrm{~h}$. Although the blood samples were collected over $24 \mathrm{~h}$, from 1900 to $1900 \mathrm{~h}$, the data have been double plotted to aid in the visualization of the leptin circadian rhythm. The plasma leptin concentrations are expressed as a percentage of the $24-\mathrm{h}$ mean $(=100 \%)$. Data points represent mean values ( \pm s.E.M.). Significance values represent a Dunnett's test comparing each plasma leptin concentration with the nadir concentration over $24 \mathrm{~h}$ within a group. Young and old males had a nocturnal elevation in plasma leptin (indicated by thick and thin arrows, respectively). A schematic of activity and rest (indicated by vertical and dashed lines, respectively) and the relationship to the timing and duration of meals (indicated by two square symbols) is shown above the lighting schedule.

also apparent. The young males had a longer period of significant nocturnal leptin elevation relative to the morning nadir $(1700-0400 \mathrm{~h}, P<0 \cdot 01)$ compared to the old males $(1700-0100 \mathrm{~h}, P<0 \cdot 05)$, whose leptin rhythm was more variable.

\section{Male body weight and plasma hormone characteristics}

The body weight, 24-h plasma leptin characteristics, morning plasma insulin and DHEAS concentrations, and 24-h mean testosterone concentrations of the males are shown in Table 1. The young males had a significantly higher mean body weight $(P<0 \cdot 05)$, but lower mean plasma leptin concentration $(P<0 \cdot 01)$ compared to young females (Student's $t$-test; $9 \cdot 5 \pm$ $0.6 \mathrm{~kg}$ and $1.3 \pm 0.2 \mathrm{ng} / \mathrm{ml}$, vs $5.9 \pm 0.4 \mathrm{~kg}$ and $1.7 \pm$ $0 \cdot 5 \mathrm{ng} / \mathrm{ml}$ ). Additionally, although there was no difference in fasted morning plasma insulin concentrations between the young and old males, the young males had a lower mean plasma leptin concentration $(P<0 \cdot 01)$ compared to the old males, which probably stems from differences in body fat content rather

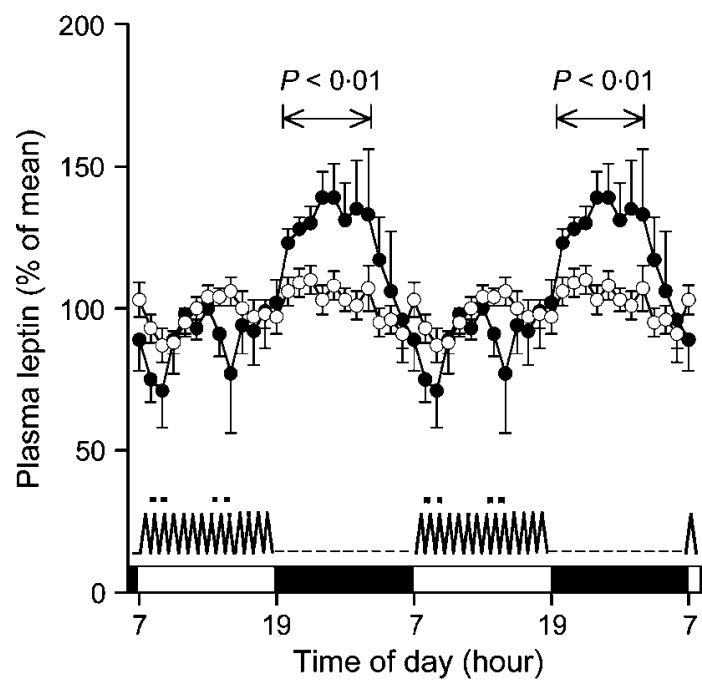

Figure 2 24-h plasma leptin concentrations in young adult $(0 ; n=4)$ female rhesus monkeys and old peri- and post-menopausal $(O ; n=8)$ female rhesus monkeys. The horizontal black and white bar on the abscissa corresponds to the $12 \mathrm{~h}$ light: $12 \mathrm{~h}$ darkness lighting schedule. The monkeys were fed two meals daily at 0800 and $1500 \mathrm{~h}$. Although the blood samples were collected over $24 \mathrm{~h}$, from 0700 to $0700 \mathrm{~h}$, the data have been double plotted to aid in the visualization of the leptin circadian rhythm. The plasma leptin concentrations are expressed as percentage of the 24 -h mean $(=100 \%)$. Data points represent mean values ( \pm S.E.M.). Significant values represent a Dunnett's test comparing each plasma leptin concentration with the nadir concentration over $24 \mathrm{~h}$ within a group. Only the young females had a significant nocturnal elevation in plasma leptin (indicated by horizontal arrows). A schematic of activity and rest (indicated by vertical and dashed lines, respectively) and the relationship to the timing and duration of meals (indicated by two square symbols) is shown above the lighting schedule.

than body weight, which was well matched for the two groups. Young males had significantly higher levels of fasted morning plasma DHEAS $(P<0 \cdot 05)$ and $24-\mathrm{h}$ mean plasma testosterone $(P<0 \cdot 0001)$.

Comparison of 24-h leptin profiles in young and old female rhesus monkeys

Significant diurnal variation of plasma leptin was also evident in the young pre-menopausal females $(P<0 \cdot 01)$, with a nocturnal elevation from 2000 to $0300 \mathrm{~h}$ (Fig. 2). Unlike their old male counterparts and young females, the old peri- and post-menopausal females had relatively constant levels of plasma leptin across the day and night. However, this agingrelated sexual dimorphism was not evident in all of the old females. The old pre-menopausal females in the mid-late follicular phase of their menstrual cycles (i.e. prior to ovulation, when plasma $17 \beta$-estradiol concentrations are rising) showed a significant elevation in plasma leptin relative to the morning nadir $(P<0 \cdot 01)$ from 1900 to $0300 \mathrm{~h}$ (Fig. 3), which was qualitatively indistinguishable from the 24-h leptin rhythm of the young females. 


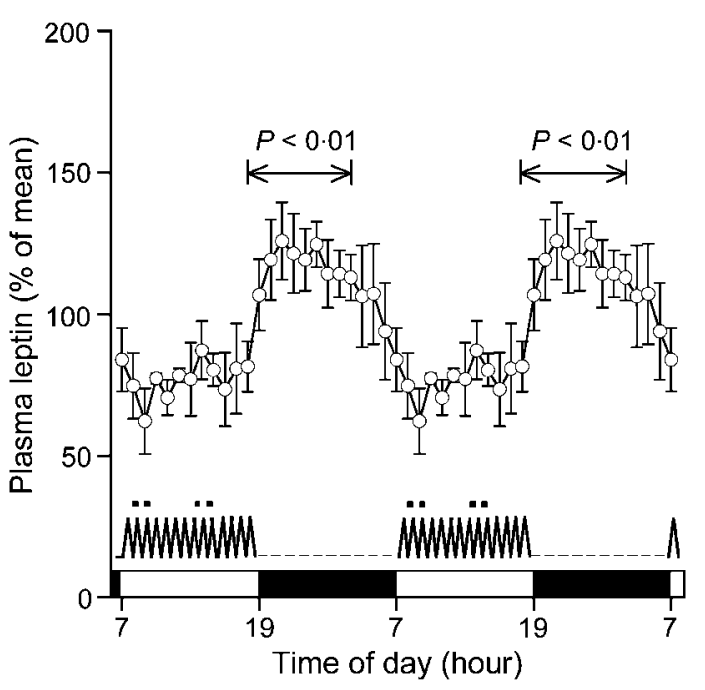

Figure 3 24-h plasma leptin concentrations in old pre-menopausal female rhesus monkeys $(n=3)$. The horizontal black and white bar on the abscissa corresponds to the $12 \mathrm{~h}$ light: $12 \mathrm{~h}$ darkness lighting schedule. The monkeys were fed two meals daily at 0800 and $1500 \mathrm{~h}$. Although the blood samples were collected over $24 \mathrm{~h}$, from 0700 to $0700 \mathrm{~h}$, the data have been double plotted to aid in the visualization of the leptin circadian rhythm. The plasma leptin concentrations are expressed as a percentage of the 24 -h mean $(=100 \%)$. Data points represent mean values $( \pm$ s.E.M.). Significant values represent a Dunnett's test comparing each plasma leptin concentration with the nadir concentration over $24 \mathrm{~h}$ within a group. Old premenopausal females had a significant nocturnal elevation in plasma leptin (indicated by horizontal arrows). A schematic of activity and rest (indicated by vertical and dashed lines, respectively) and the relationship to the timing and duration of meals (indicated by two square symbols) is shown above the lighting schedule.

\section{Female body weight and plasma hormone characteristics}

The body weight, 24-h plasma leptin characteristics, and morning plasma insulin and DHEAS concentrations of the females are shown in Table 2. An age-associated difference in plasma leptin levels and body weights was apparent in the females despite no differences in fasted morning plasma insulin levels between female groups. Compared to the young adult females, the old peri- and post-menopausal females had a significantly higher body weight $(P<0 \cdot 05)$ as well as significantly higher mean plasma leptin $(P<0 \cdot 01)$, peak $(P<0 \cdot 05)$, nadir $(P<0 \cdot 01)$, and fasting plasma leptin $(P<0 \cdot 01)$ concentrations. The old pre-menopausal females showed no difference in mean or peak plasma leptin compared to the old peri- and postmenopausal females. However, compared to the old premenopausal females, the old peri- and post-menopausal females had a significantly higher body weight $(P<0 \cdot 05)$ as well as higher nadir $(P<0 \cdot 01)$, and fasting plasma leptin $(P<0 \cdot 05)$ concentrations. The higher morning concentrations of plasma leptin in the old peri- and post-menopausal females compared to the pre-menopausal females caused a blunting of the 24-h plasma leptin variation to a constant concentration of plasma leptin throughout the 24-h day in the old peri- and

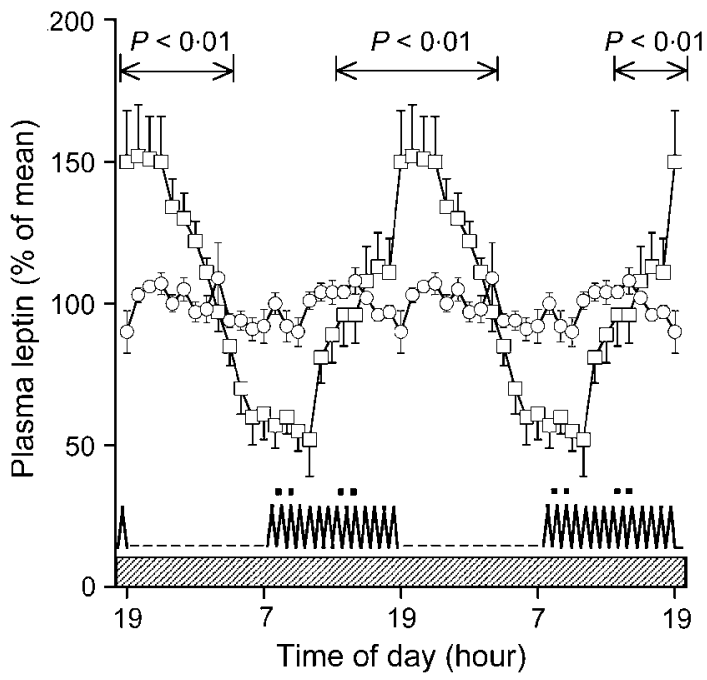

Figure 4 Circadian rhythm of plasma leptin concentrations in old male rhesus monkeys $(\square ; n=5)$ and relatively constant $24-\mathrm{h}$ plasma leptin concentrations in old peri- and post-menopausal female rhesus monkeys $(O ; n=7)$ under continuous dim illumination $(\sim 100 \mathrm{lu})$ indicated by the hatched horizontal bar on the abscissa. The monkeys were fed two meals daily at 0800 and $1500 \mathrm{~h}$. Although the blood samples were collected over $24 \mathrm{~h}$, from 1900 to $1900 \mathrm{~h}$ and from 0700 to $0700 \mathrm{~h}$ from males and females, respectively, the data have been double plotted starting at $1900 \mathrm{~h}$ to aid in the visualization of the leptin circadian rhythm. The plasma leptin concentrations are expressed as a percentage of the 24-h mean $(=100 \%)$. Data points represent mean values ( \pm s.E.M.). Significant values represent a Dunnett's test comparing each plasma leptin concentration with the nadir concentration over $24 \mathrm{~h}$ within a group. Only the old males had a significant nocturnal elevation in plasma leptin during their subjective night (indicated by horizontal arrows). A schematic of activity and rest (indicated by vertical and dashed lines, respectively) and the relationship to the timing and duration of meals (indicated by two square symbols) is shown above the lighting schedule.

post-menopausal females. A similar blunting occurred with age in morning plasma DHEAS $(P<0 \cdot 05)$ concentrations, when plasma concentrations of DHEAS typically peak, in both the old pre-menopausal and the old peri- and post-menopausal females compared to the young pre-menopausal females.

\section{Circadian nature of circulating leptin under continuous dim illumination}

To demonstrate the circadian nature of the 24-h plasma leptin rhythm, a group of old males and old peri- and post-menopausal females were maintained under constant environmental conditions. The old males showed persistence in the elevation of plasma leptin during their subjective night, from 1600 to $0200 \mathrm{~h}$ (Fig. 4). Interestingly, this elevation was more significant $(P<0 \cdot 01)$ than the one previously observed when the animals were maintained under the $12 \mathrm{~h}$ light: $12 \mathrm{~h}$ darkness lighting schedule. In contrast to the males, the old peri- and post-menopausal females failed to show a significant $(P>0.05)$ diurnal variation in their plasma leptin 


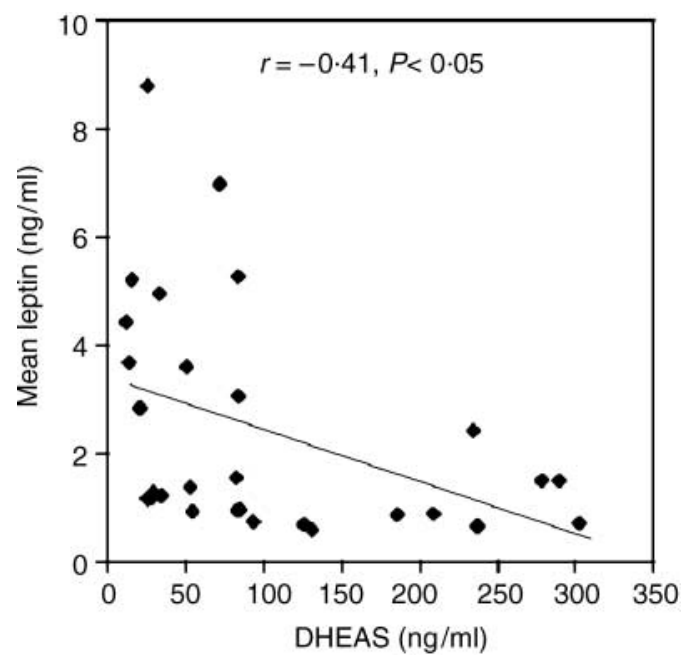

Figure 5 Correlations between plasma leptin concentrations and plasma DHEAS concentrations in young and old male and female monkeys $(n=28)$. A significant negative linear correlation is present between leptin and DHEAS. Data points represent 24-h mean leptin values and early morning (0700 h) pre-prandial DHEAS values for each individual monkey.

concentrations while maintained under constant environmental conditions (Fig. 4).

\section{Age and plasma hormone correlations}

A significant negative correlation $(P<0 \cdot 05)$ was present between 24-h mean plasma leptin concentrations and morning pre-prandial plasma DHEAS concentrations (Fig. 5). To better understand if the aging-related decline in plasma DHEAS concentrations could explain the elevation in plasma leptin levels in the old males and old peri- and postmenopausal females compared to their young counterparts, we conducted a correlation comparison with age and plasma leptin, insulin and DHEAS (Fig. 6). A significant positive linear correlation $(P<0 \cdot 001)$ was present between leptin and age in old peri- and post-menopausal females. A significant negative correlation between DHEAS and age was present in both males $(P<0 \cdot 001)$, and old peri- and post-menopausal females $(P<0 \cdot 05)$. We found no significant correlation with age and insulin in any group.

\section{Discussion}

The present study clearly demonstrates the existence of a 24-h circulating leptin rhythm in a non-human primate. This leptin rhythm is characterized by a peak at or near $2300 \mathrm{~h} \mathrm{(4} \mathrm{h}$ after lights out) and a nadir near $0700 \mathrm{~h}$ (at light on-set). Overall, therefore, these findings confirm the results from previous studies in humans (Sinha et al. 1996a, Langendonk et al. 1998, Simon et al. 1998), which showed a clear nocturnal rise in circulating leptin, while bringing new insights to the sex-specific aging of this hormonal rhythm.
Additionally, our data concur with previous non-human primate studies, in that we observed similar plasma concentrations of leptin that increased with age (Urbanski \& Pau 1998, Muehlenbein et al. 2005). However, this work advances the paucity of data regarding circulating leptin in rhesus monkeys in several ways. Unlike previous works utilizing rhesus monkeys, we were able to determine the 24-h pattern of release by utilizing a remote blood-sampling system that allowed for frequent sampling (hourly for $25 \mathrm{~h}$ ) rather than a single daytime only, or a single day and nighttime sample (Plant \& Durrant 1997, Urbanski et al. 1998, Suter et al. 2000, Muehlenbein et al. 2005), and this remote sampling technique also eliminated the potential for a stress response that may confound the observed levels of leptin. Much of the previous data on circulating leptin in the nonhuman primate pertained to the relationship between circulating leptin levels and the initiation of puberty (Plant \& Durrant 1997, Suter et al. 2000). These studies utilized young animals only and they focused exclusively on males. In contrast, we studied adult animals of different age groups as well as different sexes. Additionally, in an effort to better understand the circadian-like nature of circulating leptin, we endeavored to sample from animals in the absence of photoperiodic cues and other potential zietgebers.

Much is already known about the humoral factors that contribute to the synthesis and release of leptin. These include glucose and insulin (Considine 2001, Havel 2002), adrenal steroids (Casabiell et al. 2001, Considine 2001, Leal-Cerro et al. 2001), and the sex steroids estradiol and testosterone (Casabiell et al. 2001, Mayes \& Watson 2004). On the other hand, the underlying mechanism by which these factors exert their influence on leptin is unclear, especially the mechanism that controls leptin's 24-h rhythm. The sex-specific effects on plasma leptin we observed in rhesus monkeys were consistent with those observed in human studies (Casabiell et al. 2001, Mayes \& Watson 2004). Overall, mean values of plasma leptin in the adult female monkeys were higher than those found in males despite having lower body weights. In part, this may be due to a higher body fat content in females than in males. However, it is likely that body fat differences are not the solitary factor contributing to this sexual dimorphism. Spontaneous leptin secretion in vitro from identical adipose tissue samples produce more leptin from samples obtained from female donors than those from male donors (Casabiell et al. 1998, Casabiell et al. 2001). Gonadal sex steroids are also likely to play a role in the sex differences that are observed in plasma leptin concentrations. Studies of human omental adipose tissue in vitro demonstrated the stimulatory effect of estrogen on the release of leptin from adipose tissue of women but not men (Casabiell et al. 1998). Gender differences in circulating leptin concentrations in vivo are reversed in transsexuals receiving cross-sex steroid hormone treatment (Elbers et al. 1997), and the inappropriately high leptin levels that are observed in hypogonadal men are attenuated by testosterone replacement (Jockenhovel et al. 1997). Similarly, we observed significantly higher plasma leptin concentrations and significantly lower 

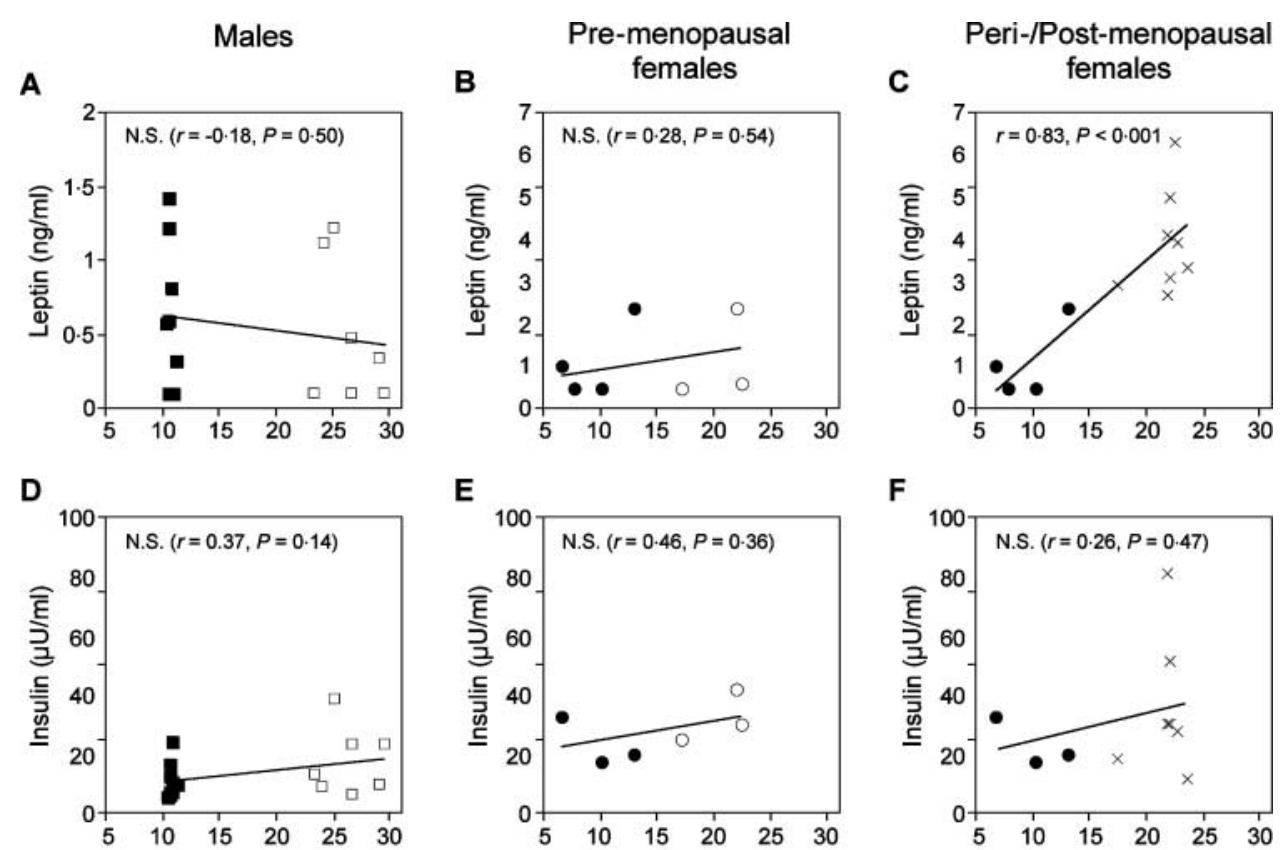

G

H
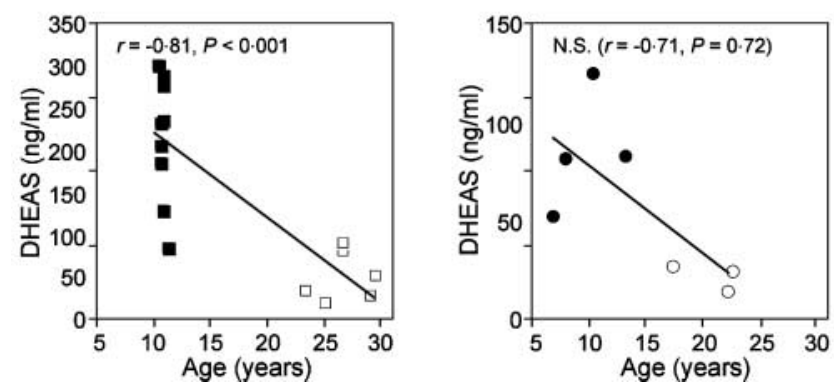

I

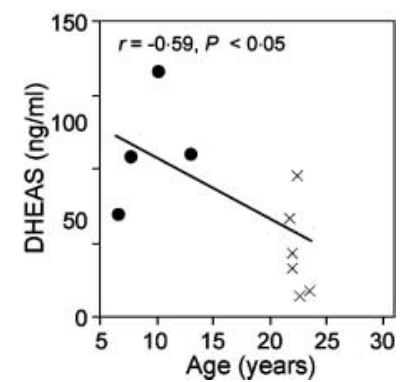

Figure 6 Correlations between plasma leptin (A-C), insulin (D-F) and DHEAS (G-I) levels with age in male $(\boldsymbol{\square}$, young; $\square$, old adults) and female $(\bullet$, young adults; $\bigcirc$, old pre-menopausal; $X$, old peri- and postmenopausal) monkeys. A significant positive linear correlation is present between leptin and age only in peri/post-menopausal females, whereas DHEAS is negatively correlated with age in both males and peripost-menopausal females. There is no significant correlation between insulin and age in any of the groups. Data points represent individual early morning $(0700 \mathrm{~h})$ pre-prandial values for each monkey.

testosterone concentrations in old males compared to young male monkeys.

In the present study, we observed a 24-h pattern of circulating leptin in male monkeys, even when they were maintained under long-term constant environmental conditions (consisting of continuous dim illumination and constant temperature while masking the vocalized social cues of other nearby animals). Although not all potential zeitgebers, or time-of-day cues, such as meal timing, could be completely ruled out in this study, the data represent the first evidence in a primate that the plasma leptin rhythm may be truly 'circadian' in nature (i.e. maintains a $\sim 24-h$ period even in the absence of external time-of-day cues). In the present study, it is possible that meal timing acts as the primary zeitgeber for the 24-h leptin rhythm. The variable of meal timing is difficult to bypass, as even under feeding ad libitum the rhesus monkey self-imposes consolidated meal times. To minimize this variability, we chose to keep meal timing at 0800 and $1500 \mathrm{~h}$ with all other external cues being held constant. Previous efforts to determine if the 24-h circulating leptin rhythm is truly circadian did not allow enough time under 'constant conditions' for subjects' endogenous circadian rhythms to be viewed as 'free-running'; instead, they showed a leptin rhythm shift after a short photoperiod change, where any circadian control of leptin release would have been masked by a shift in activity and behavior (Schoeller et al. 1997). Future studies will be needed to address the issue of 'free-running' conditions and continuous feeding or meal timing shifts to determine the primary driving force behind leptin's temporal release pattern. 
In the previous studies, Franceschini et al. (1999) and Zhao et al. (2002) sought to identify aging-related changes in circulating 24-h leptin concentrations and found that there were minor changes in amplitude and overall mean levels respectively, but in both cases the 24-h leptin rhythm was generally preserved with old age. We were able to advance these previous observations in several ways. First, we performed more frequent blood samples to generate a more detailed leptin profile than the previous two studies. Secondly, we chose animals of appropriately young ages for our control groups to compare with appropriately old-aged monkeys. In the Franceschini et al. (1999) study, it is possible that more significant changes in the 24-h leptin rhythms would have been observed if the old group ( $72-87$ years) would have been compared to a younger control group rather than middleaged men (35-50 years). Additionally, in the Zhao et al. (2002) study, the men varied in age from 31 to 63 years. It is possible that this span in ages was insufficient to disclose changes in the 24-h rhythmicity of leptin other than the typical age-associated increases in overall leptin concentrations and increases in body fat. Furthermore, both the two previous studies utilized male subjects exclusively. Age-related changes to endocrine rhythms are commonly different in males compared to females, and thereby warrant sex-specific investigation especially with respect to the endocrine changes occurring around the time of menopause for women. The effect of age on plasma leptin concentrations in women remains controversial (Mayes \& Watson 2004). Parts of the discrepancies in leptin concentrations found in aging women are likely due to the complications of their variable hormonal milieus associated with the transition into menopause and hormone therapies. For this reason, we chose to divide our old female group into a pre-menopausal group and a peri/post-menopausal group.

An unexpected key finding in the present study was that the circadian leptin rhythm was preserved in old males, but not in old peri- and post-menopausal females. While being exposed to constant environmental conditions and during the $12 \mathrm{~h}$ light: $12 \mathrm{~h}$ darkness lighting schedule, these old females displayed a relatively constant level of plasma leptin over $24 \mathrm{~h}$ with no clear evidence for a nocturnal peak. The elevation in morning plasma leptin levels in peri- and post-menopausal females could not be accounted for by any differences in food intake or plasma insulin levels. This aging-associated sexual dimorphism of the 24-h circulating leptin pattern may be indicative of differences in the aging of the circadian system per se, being more pronounced or advanced in old females compared to old males. Evidence for the dampening of other circadian hormone rhythms with advancing age indicates that this may indeed be the case (Touitou et al. 1997, Gundlah et al. 2000, Touitou \& Harris 2000, Downs et al. 2001, Pandi-Perumal et al. 2002, Urbanski et al. 2004). For example, we have previously shown that in female monkeys, there is a dramatic attenuation in the amplitude of the DHEAS circadian rhythm around the time of menopause (Downs et al. 2001), whereas the circadian pattern (and overall mean plasma levels) of this adrenal hormone are maintained to a much later age in males (Urbanski et al. 2004). Although the old males did not appear to lose their nocturnal plasma leptin peak, their rhythms did differ slightly from those of young males; the plasma levels were more variable and the duration of the nocturnal peak was shorter, which is consistent with previous observations (Franceschini et al. 1999, Zhao et al. 2002).

The reason for the disappearance of the 24-h plasma leptin rhythm in many of the old females is unclear, but it may be related to aging-associated changes in the sex-steroid environment. In support of this view is the observation that the nocturnal plasma leptin peak persisted in the old pre-menopausal females, but not in the old peri- and post-menopausal females despite identical meal timing, food intake, and fasted plasma insulin levels. Although an agingrelated decrease in sex-steroid secretion from the ovaries may play a causal role in the suppression of a $24-\mathrm{h}$ variation in plasma leptin, one cannot rule out the possibility that the aging-associated decrease in DHEA, and its sulfated form DHEAS, from the adrenal gland is also involved. In monkeys, DHEA(S) has a circadian rhythm, characterized by a morning peak, which is in antiphase with the circadian plasma leptin rhythm (Downs et al. 2001, Urbanski et al. 2004). Furthermore, DHEA(S) is a precursor to testosterone, and previous work has shown that androgens such as testosterone can inhibit the release of leptin (Elbers et al. 1997, Jockenhovel et al. 1997, Wabitsch et al. 1997, Machinal-Quélin et al. 2002). Therefore, it is plausible that the absence of a circadian leptin rhythm in the old peri- and post-menopausal females, stems from a loss of androgenmediated leptin inhibition via DHEA(S). In support of this view, we found a marked attenuation in plasma DHEAS in old females. Although old males also displayed a significant attenuation in plasma DHEAS concentrations, overall they were twice that of the old females. Additionally, an agingrelated decline in plasma testosterone concentrations in the males may help to maintain a pronounced 24-h leptin rhythm, as the nighttime peak of testosterone declines in old males so may the testosterone-mediated inhibition of peak plasma leptin levels. Further, elevated plasma testosterone in males compared to females may help to explain the commonly seen differences in plasma leptin concentrations between males and females even after correction for differences in body fat content (Havel et al. 1996, Ostlund et al. 1996, Rosenbaum et al. 1996, Kennedy et al. 1997, Lahlou et al. 1997, Licinio et al. 1998, Saad et al. 1998). However, the lower mean plasma leptin concentration observed in the young males (compared to the young females and old males) is likely to be at least partially attributable to their lower body fat content.

At present, the pathophysiological significance of a reduced diurnal variation in plasma leptin during old age is largely unknown, but such changes have the potential to contribute to disrupted eating patterns and body weight regulation and bone remodeling, as well as to perturbation of consolidated 
night-time sleep. The loss of bone mass in post-menopausal women leading to osteoporosis is of great concern and a deeper understanding of the causal factors is especially important. Although gonadal failure and the following loss of sex-steroids are considered to be the primary reason for the loss of bone mass in post-menopausal women; recent findings demonstrate that leptin, acting separately from its associated feeding and reproductive neurocircuitry, operates upon the sympathetic nervous system to regulate bone remodeling (Ducy et al. 2000, Elefteriou et al. 2005). When leptin was replaced in leptin deficient mice, their elevated bone mass declined (Ducy et al. 2000). Leptin exerted its effects through the sympathetic nervous system to increase the production of receptor activator nuclear factor-kappaB (RANK) ligand, which in turn stimulated the formation of osteoclasts (Elefteriou et al. 2005). Moreover, an intact circadian clock mechanism was required for leptin's effect on bone (Fu et al. 2005). These new insights emphasize the potential pathophysiological significance of the elevated baseline levels and the loss of leptin rhythmicity we find in old peri- and post-menopausal female rhesus monkeys. Additionally, it has been suggested that a nocturnal rise in leptin curbs nighttime hunger, and thereby may help to maintain consolidated sleep (Sinha et al. 1996a, 1996b). However, this explanation does not account for the observation that nocturnal rodents also have elevated circulating leptin concentrations at night, even though they are awake (Saladin et al. 1995). Several factors that influence leptin release (Casabiell et al. 2001, Considine 2001, Leal-Cerro et al. 2001, Havel 2002, Mayes \& Watson 2004) are known to change with age (Forbes 1987, Rosenbaum et al. 1996, Touitou et al. 1997, Moller et al. 1998, Touitou \& Haus 2000, Pandi-Perumal et al. 2002, Urbanski et al. 2004). It has been demonstrated that an increase in body fat content in humans is associated with a dampened diurnal variation and pulsatility in plasma leptin secretion (Matkovic et al. 1997). However, an aging-related gain in body fat is unlikely to be the basis for the loss of diurnal variation in plasma leptin that was observed in the old peri- and post-menopausal females, because a strong diurnal variation in plasma leptin was preserved in age and body weight-matched old premenopausal females. Despite this match in age and body weight, old peri- and post-menopausal females had significantly higher baseline plasma leptin concentrations, which is consistent with previous reports (Havel et al. 1996, Rosenbaum et al. 1996, Licinio et al. 1998, Saad et al. 1998). While the cause of the aging-related loss of a circadian leptin rhythm and an elevation in baseline leptin in old peri- and postmenopausal females is uncertain, it is likely that the higher baseline concentration of plasma leptin in old peri- and postmenopausal females is responsible for masking its circadian rhythm and possibly contributing to an aging-related loss of bone.

In summary, this study demonstrates that the 24-h variation of plasma leptin persists under long-term constant environmental conditions, suggesting that the leptin rhythm may truly be circadian in nature. Additionally, the study shows an aging-related sexually dimorphic loss of the circulating leptin circadian rhythm in the female rhesus monkey, which may be related to loss of circulating steroid concentrations around the time of menopause.

\section{Acknowledgements}

We wish to thank Vasilios T. Garyfallou and Laura L. James at the ONPRC for their work in maintaining catheter patency, and the ONPRC Division of Animal Resources for their animal care.

\section{Funding}

This work was supported by NIH grants: AG-023477, AG19100, AG-19914, HD-29186, RR-00163, and RR-14451. The authors declare that there was no conflict of interest that would prejudice the impartiality of the research reported.

\section{References}

Aghazadeh-Sanai N, Downs JL \& Urbanski HF 2005 Effect of aging and caloric restriction on circadian hormone release in female rhesus macaques. Society for Neuroscience 35th Annual Meeting, Washington, DC, USA, prog. 521.15 (Abstract).

Balligand JL, Brichard SM, Brichard V, Desager JP \& Lambert M 1998 Hypoleptinemia in patients with anorexia nervosa: loss of circadian rhythm and unresponsiveness to short-term refeeding. European Journal of Endocrinology 138 415-420.

Campfield LA, Smith FJ, Guisez Y, Devos R \& Burn P 1995 Recombinant mouse $\mathrm{OB}$ protein: evidence for a peripheral signal linking adiposity and central neural networks. Science 269 546-549.

Considine RV 2001 Regulation of leptin production. Reviews in Endocrine and Metabolic Disorders 2 357-363.

Casabiell X, Piñeiro V, Peino R, Lage M, Camina J, Gallego R, Vallejo LG, Dieguez C \& Casanueva FF 1998 Gender differences in both spontaneous and stimulated leptin secretion by human omental adipose tissue in vitro; Dexamethasone and extradiol stimulate leptin release in women, but not in men. Journal of Clinical Endocrinology and Metabolism 83 2149-2155.

Casabiell X, Piñeiro V, Vega F, De la Cruz LF, Diéguez C \& Casanueva FF 2001 Leptin, reproduction and sex steroids. Pituitary 4 93-99.

Downs JL, Garyfallou VT, Urbanski HF. 2001 Aging-related changes in the circadian release pattern of DHEAS and cortisol in female rhesus monkeys. Program of the 83rd Annual Meeting of the Endocrine Society, Denver, CO, USA, p. 244 (Abstract).

Downs JL \& Urbanski HF 2003 Influence of age and sex on the 24-hour pattern of circulating leptin concentrations. Program of the 85th Annual Meeting of the Endocrine Society, Philadelphia, PA, USA, p 183 (Abstract).

Ducy P, Amling M, Takeda S, Priemel M, Schilling AF, Beil FT, Shen J, Vinson C, Rueger JM \& Karsenty G 2000 Leptin inhibits bone formation through a hypothalamic relay: a central control of bone mass. Cell 100 197-207.

Elbers JMH, Asscheman H, Seidell JC, Frölich M, Meinders AE \& Gooren LJG 1997 Reversal of the sex hormone difference in serum leptin levels upon cross-sex hormone administration in transsexuals. Journal of Clinical Endocrinology and Metabolism 82 3267-3270. 
Elefteriou F, Ahn JD, Takeda S, Starbuck M, Yang X, Liu X, Kondo H, Richards WG, Bannon TW, Noda M et al. 2005 Leptin regulation of bone resorption by the sympathetic nervous system and CART. Nature $\mathbf{4 3 4}$ 514-520.

Forbes GB 1987 Human Body Composition: Growth, Aging, Nutrition and Activity. New York, NY, USA, Springer-Verlag Publishing Co.

Franceschini R, Corsini G, Cataldi A, Fiorucci A, Tenerelli P, Rolandi E \& Barreca T 1999 Twenty-four-hour variation in serum leptin in the elderly. Metabolism 48 1011-1014.

Fu L, Patel MS, Bradley A, Wagner EF \& Karsenty G 2005 The molecular clock mediates leptin-regulated bone formation. Cell 122 803-815.

Gundlah C, Kohama SG, Mirkes SJ, Garyfallou VT, Urbanski HF \& Bethea CL 2000 Distribution of estrogen receptor beta $(E R \beta)$ mRNA in hypothalamus, midbrain and temporal lobe of spayed macaque: continued expression with hormone replacement. Molecular Brain Research 76 191-204.

Halaas JL, Gajiwala KS, Maffei M, Cohen SL, Chait BT, Rabinowitz D, Lallone RL, Burley SK \& Friedman JM 1995 Weight-reducing effects of the plasma protein encoded by the obese gene. Science 269 543-546.

Havel PJ 2002 Control of energy homeostasis and insulin action by adipocyte hormones: leptin, acylation stimulating protein, and adiponectin. Current Opinion in Lipidology 13 51-59.

Havel PJ, Kasim-Karakas S, Dubuc GR, Mueller W \& Phinney SD 1996 Gender differences in plasma leptin concentrations. Nature Medicine $\mathbf{2}$ 949-950.

Jockenhovel F, Blum WF, Vogel E, Englaro P, Muller-Wieland D, Reinwein D, Rascher W \& Krone W 1997 Testosterone substitution normalizes elevated serum leptin levels in hypogonadal men. Journal of Clinical Endocrinology and Metabolism 82 2510-2513.

Kennedy A, Gettys TW, Watson P, Wallace P, Ganaway E, Pan Q \& Garvey WT 1997 The metabolic significance of leptin in humans: gender-based differences in relationship to adiposity, insulin sensitivity, and energy expenditure. Journal of Clinical Endocrinology and Metabolism 82 1293-1300.

Lahlou N, Landais P, De BD \& Bougneres PF 1997 Circulating leptin in normal children and during the dynamic phase of juvenile obesity: relation to body fatness, energy metabolism, caloric intake, and sexual dimorphism. Diabetes 46 989-993.

Langendonk JG, Pijl H, Toornvliet AC, BurggraafJ, Frölich M, Schoemaker RC, Doornbos J, Cohen AF \& Meinders AE 1998 Circadian rhythm of plasma leptin levels in upper and lower body obese women: influence of body fat distribution and weight loss. Journal of Clinical Endocrinology and Metabolism $\mathbf{8 3}$ 1706-1712.

Laughlin GA \& Yen SS 1997 Hypoleptinemia in women athletes: absence of a diurnal rhythm with amenorrhea. Journal of Clinical Endocrinology and Metabolism 82 318-321.

Leal-Cerro A, Soto A, Martínez MA, Diéguez C \& Casanueva FF 2001 Influence of cortisol status on leptin secretion. Pituitary 4 111-116.

Licinio J, Mantzoros C, Negrão AB, Cizza G, Wong ML, Bongiorno PB, Chrousos GP, Karp B, Allen C, Flier JS \& Gold PW 1997 Human leptin levels are pulsatile and inversely related to pituitary-adrenal function. Nature Medicine 3 575-579.

Licinio J, Negrão AB, Mantzoros C, Kaklamani V, Wong ML, Bongiorno PB, Negro PP, Mulla A, Veldhuis JD, Cearnal L et al. 1998 Sex differences in circulating human leptin pulse amplitude: clinical implications. Journal of Clinical Endocrinology and Metabolism 83 4140-4147.

Machinal-Quélin F, Dieudonné MN, Pecquery R, Leneveu MC \& Giudicelli Y 2002 Direct in vitro effects of androgens and estrogens on ob gene expression and leptin secretion in human adipose tissue. Endocrine 18 179-184.

Matkovic V, Ilich JZ, Badenhop NE, Skugor M, Clairmont A, Klisovic D \& Landoll JD 1997 Gain in body fat is inversely related to the nocturnal rise in serum leptin level in young females. Journal of Clinical Endocrinology and Metabolism 82 1368-1372.

Mayes JS \& Watson GH 2004 Direct effects of sex steroid hormones on adipose tissues and obesity. Obesity Reviews 5 197-216.

Moller N, O’Brien P \& Nair KS 1998 Disruption of the relationship between fat content and leptin levels with ageing in humans. Journal of Clinical Endocrinology and Metabolism 83 931-934.
Muehlenbein MP, Campbell BC, Richards RJ, Watts DP, Svec F, Falkenstein KP, Murchison MA \& Myers L 2005 Leptin, adiposity, and testosterone in captive male macaques. American Journal of Physical Anthropology 127 335-341.

Ostlund RJ, Yang JW, Klein S \& Gingerich R 1996 Relation between plasma leptin concentration and body fat, gender, diet, age, and metabolic covariates. Journal of Clinical Endocrinology and Metabolism $\mathbf{8 1}$ 3909-3913.

Pandi-Perumal SR, Seils LK, Kayumov L, Ralph MR, Lowe A, Moller H \& Swaab DF 2002 Senescence, sleep, and circadian rhythms. Ageing Research Reviews 1 559-604.

Pelleymounter MA, Cullen MJ, Baker MB, Hecht R, Winters D, Boone T \& Collins F 1995 Effects of the obese gene product on body weight regulation in ob/ob mice. Science 269 540-543.

Plant TM \& Durrant AR 1997 Circulating leptin does not appear to provide a signal for triggering the initiation of puberty in the male rhesus monkey (Macaca mulatta). Endocrinology 138 4505-4508.

Purnell JQ \& Samuels MP 1999 Levels of leptin during hydrocortisone infusions that mimic normal and reversed diurnal cortisol levels in subjects with adrenal insufficiency. Journal of Clinical Endocrinology and Metabolism $\mathbf{8 4}$ 3125-3128.

Resko JA, Malley A, Begley D \& Hess DL 1973 Radioimmunoassay of testosterone during fetal development of the rhesus monkey. Endocrinology 93 156-161.

Resko JA, Norman RL, Niswender GD \& Spies HG 1974 The relationship between progestins and gonadotropins during the late luteal phase of the menstrual cycle in rhesus monkeys. Endocrinology 94 128-135.

Resko JA, Ploem JG \& Stadelman HL 1975 Estrogens in fetal and maternal plasma of the rhesus monkey. Endocrinology 97 425-430.

Rosenbaum M, Nicolson M, Hirsch J, Heymsfield SB, Gallagher D, Chu F \& Leibel RL 1996 Effects of gender, body composition, and menopause on plasma concentrations of leptin. Journal of Clinical Endocrinology and Metabolism 81 3424-3427.

Saad MF, Riad-Gabriel MG, Khan A, Sharma A, Michael R, Jinagouda SD, Boyadjian R \& Steil GM 1998 Diurnal and ultradian rhythmicity of plasma leptin: effects of gender and adiposity. Journal of Clinical Endocrinology and Metabolism 83 453-459.

Saladin R, De Vos P, Guerre-Millo M, Leturge A, Girard J, Staels B \& Auwerx J 1995 Transient increase in obese gene expression after food intake or insulin administration. Nature 377 527-529.

Schoeller DA, Cella LK, Sinha MK \& Caro JF 1997 Entrainment of the diurnal rhythm of plasma leptin to meal timing. Journal of Clinical Investigation 100 1882-1887.

Schwartz WJ 1993 A clinician's primer on the circadian clock: its localization, function, and resetting. Advances in Internal Medicine $\mathbf{3 8}$ 81-106.

Simon C, Gronfier C, Schlienger JL \& Brandenberger G 1998 Circadian and ultradian variations of leptin in normal man under continuous enteral nutrition: relationship to sleep and body temperature. Journal of Clinical Endocrinology and Metabolism 83 1893-1899.

Sinha MK, Ohannesian JP, Heiman ML, Kriauciunas A, Stephens TW, Magosin S, Marco C \& Caro JF 1996a Nocturnal rise of leptin in lean, obese, and non-insulin-dependent diabetes mellitus subjects. Journal of Clinical Investigation 97 1344-1347.

Sinha MK, Sturis J, Ohannesian J, Magosin S, Stephens T, Heiman ML, Polonsky KS \& Caro JF $1996 b$ Ultradian oscillations of leptin secretion in humans. Biochemical and Biophysical Research Communications 228 733-738.

Stephens TW, Basinski M, Bristow PK, Bue-Valleskey JM, Burgett SG, Craft L, Hale J, Hoffmann J, Hsiung HM, Kriauciunas A et al. 1995 The role of neuropeptide $\mathrm{Y}$ in the antiobesity action of the obese gene product. Nature 377 530-532.

Støving RK, Vinten J, Handberg A, Ebbesen EN, Hangaard J, Hanesn-Nord M, Kristiansen J \& Hagen C 1998 Diurnal variation of the serum leptin concentration in patients with anorexia nervosa. Clinical Endocrinology 48 761-768.

Suter KJ, Pohl CR \& Wilson ME 2000 Circulating concentrations of nocturnal leptin, growth hormone and insulin-like growth factor-I 
increase before the onset of puberty in agonadal male monkeys: potential signals for the initiation of puberty. Journal of Clinical Endocrinology and Metabolism 85 808-814.

Touitou Y \& Haus E 2000 Alterations with aging of the endocrine and neuroendocrine circadian system in humans. Chronobiology International 17 369-390.

Touitou Y, Bogdan A, Haus E \& Touitou C 1997 Modifications of circadian and circannual rhythms with aging. Experimental Gerontology 32 603-614.

Urbanski HF \& Pau KYF 1998 A biphasic developmental pattern of circulating leptin in the male rhesus macaque. Endocrinology 139 2284-2286.

Urbanski HF, Garyfallou VT, Kohama SG \& Hess DL 1997 Alpha-adrenergic receptor antagonism and N-methyl-D-aspartate (NMDA) induced luteinizing hormone release in female rhesus macaques. Brain Research $\mathbf{7 4 4}$ 96-104.

Urbansiki HF, Downs JL, Garyfallou VT, Mattison JA, Lane MA, Roth GS \& Ingram DK 2004 Effect of caloric restriction on the 24-hour plasma DHEAS and cortisol profiles of young and old male rhesus macaques. Annals of the New York Academy of Sciences 1019 443-447.
Wabitsch M, Blum WF, Muche R, Braun M, Hube F, Rascher W, Heinze E, Teller W \& Hauner H 1997 Contribution of androgens to the gender difference in leptin production in obese children and adolescents. Journal of Clinical Investigation 100 808-813.

Weigle DS, Bukowski TR, Foster DC, Holderman S, Kramer JM, Lasser G, Lofton-Day CE, Prunkard DE, Raymond C \& Kuijper JL 1995

Recombinant ob protein reduces feeding and body weight in the ob/ob mouse. Journal of Clinical Investigation 96 2065-2070.

Zhang Y, Proenca R, Maffei M, Barone M, Leopold L \& Friedman JM 1994 Positional cloning of the mouse obese gene and its human homologue. Nature $372425-432$.

Zhao ZY, Fu YR, Li XH, Li YY, Bogdan A \& Touitou Y 2002 Age-related modifications of circadian rhythm of serum leptin in healthy men. Gerontology 48 309-314.

Received 22 February 2006

Accepted 29 March 2006

Made available online as an Accepted Preprint 13 April 2006 